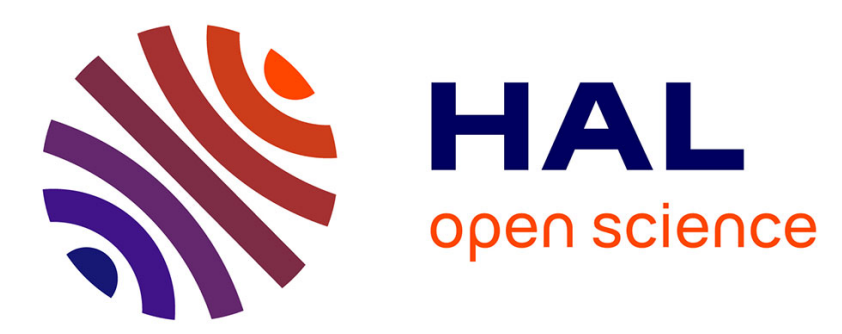

\title{
Effect of the driving force on nanoparticles growth and shape: an opto-electrochemical study
}

Jean-Marc Noël, Mathias Miranda Vieira, Vitor Brasiliense, Jean-François

Lemineur, Catherine Combellas, Frédéric Kanoufi

\section{- To cite this version:}

Jean-Marc Noël, Mathias Miranda Vieira, Vitor Brasiliense, Jean-François Lemineur, Catherine Combellas, et al.. Effect of the driving force on nanoparticles growth and shape: an optoelectrochemical study. Nanoscale, 2020, 10.1039/C9NR09419A . hal-02447120

HAL Id: hal-02447120

https://hal-univ-paris.archives-ouvertes.fr/hal-02447120

Submitted on 21 Jan 2020

HAL is a multi-disciplinary open access archive for the deposit and dissemination of scientific research documents, whether they are published or not. The documents may come from teaching and research institutions in France or abroad, or from public or private research centers.
L'archive ouverte pluridisciplinaire HAL, est destinée au dépôt et à la diffusion de documents scientifiques de niveau recherche, publiés ou non, émanant des établissements d'enseignement et de recherche français ou étrangers, des laboratoires publics ou privés. 


\title{
Effect of the driving force on nanoparticles growth and shape: an opto-electrochemical study
}

Received 00th January 20xx, Accepted 00th January 20xx DOI: $10.1039 / x 0 x x 00000 x$

\author{
Jean-Marc Noël,* Mathias Miranda Vieira, Vitor Brasiliense, Jean-Francois Lemineur, Catherine \\ Combellas and Frédéric Kanoufi*
}

\begin{abstract}
Most protocols developed to synthesize nanoparticles (NPs) and to control their shape are inspired from nucleation and growth theories. However, to rationalize the mechanisms of the shape-selective synthesis of NPs, experimental strategies allowing to probe in situ the growth of NPs are meant. Herein, metal Au or Ag nanoparticles (NPs) are produced by reaction of a metallic ion precursor with a reversible redox reducer. The process is explored by an oxidative electrosynthesis strategy using a sacrificial $\mathrm{Au}$ or $\mathrm{Ag}$ ultramicroelectrode to both trigger the metallic ion generation and control the local concentrations of the different reactants. The effect of the driving force for the metallic ions reduction over metal NP growth dynamics is inspected in situ and in real time at the single NP level by high-resolution optical microscopy from the tracking of the Brownian trajectories of the growing NPs in solution. The NPs reductive growth/oxidative etching thermodynamics, and consequently the NPs shape, are shown to be controlled electrochemically by the reversible redox couple, while the intervention of an $A u(I)$ intermediate ion is suggested to account for the formation of gold nanocubes.
\end{abstract}

\section{Introduction}

Noble-metal nanoparticles (NPs) are of great interest because of their distinct physicochemical properties compared to bulk materials, such as their size or shape that have a significant influence on their chemical reactivity, catalysis or for the design of plasmonic materials. ${ }^{1}$ In order to tailor the final structure of NPs it is then crucial to identify and control the parameters influencing their growth mechanism. If the synthetic control over NP size is supported by mechanistic and modelling considerations, apprehending their nucleation and growth $^{2-4}$ to explain the morphology of NPs during their synthesis is still challenging. It has been shown that the shape of NPs is set up during the growth phase, ${ }^{5}$ however the selection of shape is not only related to the transport of the different building blocks involved (metallic ions, metal nuclei, reducers,...) but also to the intricate thermodynamics and kinetics of metal growth, restructuring and redissolution. It makes shape selective NP growth a nonequilibrium process for which either computer-aided simulations ${ }^{6}$ or experimental

Université de Paris, ITODYS, CNRS UMR 7086, 15 rue J.A. de Baïf, F-75013 Paris, France.

E-mail: jean-marc.noel@univ-paris-diderot.fr, frederic.kanoufi@univ-parisdiderot.fr.

Electronic Supplementary Information (ESI) available: Videos SV1-3; Description of the videos; $\mathrm{Au}$ and $\mathrm{Ag}$ NPs SEM images with chronoamperometric curves; Voltammetry of Au UME in $\mathrm{Fe}^{2+}$ or $\mathrm{Fe}(\mathrm{bpy})_{3}{ }^{2+}$ solutions; MSD analysis of AgNF and AgNCs electrogeneration; Optical vs MSD particle sizing; Ag NPs growth rate distributions; Cumulative frequency growth rates; Evidencing the dissolution of AuNC from growth rates distributions; Principle of growth rate estimate from MSD analysis. See DOI: 10.1039/x0xx00000x strategies probing in situ the time-resolved growth of NPs ${ }^{3-9}$ are meant to rationalize their formation mechanism. In this context, strategies relying on single NP inspection using high resolution microscopic observation are currently pursued. Whereas Transmission Electron Microscopy (TEM) enables high -in situ or ex situ- spatial and temporal resolution observations of various dynamic phenomena at the single NP level, including nucleation, ${ }^{10}$ growth, ${ }^{9,11}$ etching, ${ }^{12,13}$ or transformation, ${ }^{14^{-16}}$ it is an expensive setup and the invasive electron beam strongly interferes with the chemical reduction of metal salts, ${ }^{17}$ making the study of the effect of different synthesis parameters on the final NP structure difficult. Moreover, since it is limited to a low depth of field, it provides images of samples in confined spaces, which may exalt surface compared to volume phenomena, and limit the amount of NPs studied in a single experiment. Alternatively, optical microscopies have the advantages of high throughput, high sensitivity, with high lateral and temporal resolution operando imaging of NPs dynamic processes. ${ }^{18}$ Such strategies have been coupled to electrochemistry to reveal, in 2D or 3D, insights into in situ bulk processes, such as NPs sizing and transport ${ }^{19-21}$ as well as surface and (electro)chemical transformations. ${ }^{22-24}$ This work aims at investigating, in situ and at the single entity level, structure-activity relationships dictating the dynamics of the growth of metallic, herein $\mathrm{Au}$ and $\mathrm{Ag}$, NPs. Systematic mechanistic investigations in this area require high throughput and temporal resolution in situ monitoring of the reaction, together with a fine control over the experimental synthetic conditions such as the metal precursor to reducer concentration ratio, the reducer strength, temperature, etc... 
The in situ and real time monitoring is provided here through a dark field optical microscopy, while the control of the experimental synthetic conditions is afforded by a multi-facet electrochemical strategy. On one hand, if most NP synthetic routes employ irreversible reducers, this work focuses on the use of reversible redox couples, which offer several advantages. Firstly, the reducing strength, measured through its standard redox potential, $\mathrm{E}^{\circ}$, and in turn the driving force of the reduction of a metallic salt, is easily modulated through its chemical structure. Here, $\mathrm{Fe}$ (II) organometallic complexes are used, the $\mathrm{E}^{\circ}$ of which is modulated by an appropriate choice of ligands, as recently mentioned. ${ }^{25}$ It is also a simple way to investigate the role of the driving force of the reduction of the metal precursor ions on the synthesis of Ag or Au metal NPs. Secondly, the NP formation will produce an, also reversible, oxidant (Fe(III)), which may also participate in the etching of the NP surface. Oxidative etching strategies are pertinent in the preferential synthesis of single-crystal particles. The presence of both the reducer and the oxidant of the $\mathrm{Fe}(\mathrm{II}) / \mathrm{Fe}$ (III) redox couple may then bring some control over the shape and growth dynamics of the NPs. ${ }^{26,27}$ Solutions containing both components of a redox couple can be easily electrogenerated by a polarized electrode. It actually affords a spatial control within the diffusion layer of the electrode of the $\mathrm{Fe}(\mathrm{II}) / \mathrm{Fe}$ (III) ratio, and therefore over their chemical activity. Such strategy has been recently highlighted for in situ electrochemical generation of both the activating and deactivating components for the controlled living growth of polymers, by electrochemical mediated atom transfer radical polymerization (ATRP). ${ }^{28}$

On the other hand, the ratio of $\mathrm{Fe}(\mathrm{II}) / \mathrm{Fe}$ (III) NP-tailoring components is triggered electrochemically by the control of the polarization sequence of the electrode. It is a means to address fast growth processes with high temporal resolution, which are difficult to analyze kinetically under usual synthetic conditions where the growth mechanism is coupled to the reactants mixing step.

Finally, electrochemistry can also be used to generate the NP metal precursor. By appropriate anodic polarization, a sacrificial metal electrode, here $\mathrm{Au}$ or $\mathrm{Ag}$, is electro-dissolved, generating metallic ions serving as the NP material precursor. Such strategy has already been used to synthesize colloidal metallic or metal oxides NPs, ${ }^{29,30}$ metallic $^{31}$ or bimetallic ${ }^{32}$ nanoclusters at large scale.

These three facets are combined here to electrogenerate, as illustrated in Scheme $1 \mathrm{~A}$, reactive solutions containing metal, here $\mathrm{Au}$ or $\mathrm{Ag}$, NP precursors and $\mathrm{Fe}(\mathrm{II}) / \mathrm{Fe}(\mathrm{III})$ reducer/oxidant. Particularly, we investigate the role of the driving force of the metal ion reduction by the reducing agent on the NP shape and growth rate. The growth of individual NPs within the electrogenerated reactant concentration gradients is monitored in situ by dark field optical microscopy, as shown in Scheme 1B. Such in situ dynamic NP sizing ${ }^{20,33}$ is used to correlate individual NP growth rates to the metal salt reduction driving force, providing mechanistic insight at the single NP level.

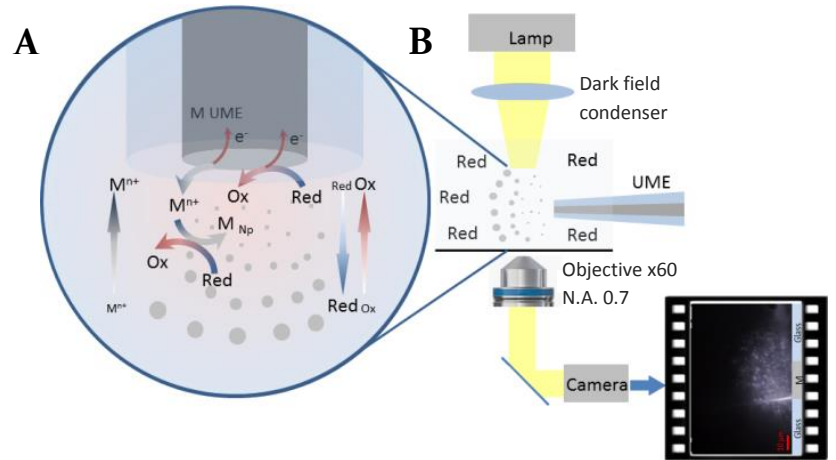

Scheme 1. Principle of NPs electrosynthesis by electrodissolution of a sacrificial ultramicroelectrode (UME) of metal $M$, in the presence of a reversible electron donor, Red, in solution: the anodic polarization of the UME ( $E_{\mathrm{UME}}$ ) generates in its vicinity concentration gradients of $\mathrm{M}^{\mathrm{n}+}$ by dissolution of $\mathrm{M}$, Red and Ox. The presence of all three components at controlled concentrations, from a control of the current ( $\mathrm{i}_{\mathrm{UME}}$ ), allows the production in the diffusion layer of the UME of NPs of M whose presence (bright features in image) and growth dynamics is probed in situ by dark field optical microscopy (B).

\section{Materials and methods}

\subsection{Materials}

Iron(II) sulphate heptahydrate $99+\%\left(\right.$ FellSO $\left._{4} \cdot 7 \mathrm{H}_{2} \mathrm{O}\right)$ and $\mathrm{KCl}$ 99.5\% were purchased from Acros Organics, $\mathrm{KPF}_{6} 98 \%$ and $\mathrm{FcMeOH}$ from Sigma-Aldrich and tris(dipyridyl)Iron(II) $\left(\mathrm{Fe}(\mathrm{bpy})_{3}{ }^{2+}\right)$ was homemade.

Homemade ultramicroelectrodes, UMEs, were fabricated using $1.0 \mathrm{~mm} / 0.5 \mathrm{~mm}$ (outer diameter/inner diameter) borosilicate glass capillaries (Sutter Instruments, Novato, California), $25 \mu \mathrm{m}$ diameter Au or Ag wires (99.99\%, Goodfellow Cambridge Ltd., Huntingdon, England), and a laser pipette puller (P2000, Sutter Instruments). The obtained $25 \mu \mathrm{m}$ diameter disc UMEs were carefully polished on polishing aluminum oxide tape $(3 \mu \mathrm{m})$ from Precision Surfaces International (Houston, Texas).

\subsection{Electrochemical measurements}

They were performed using a CHI660A or 760E instrument ( $\mathrm{CH}$-Instruments). A 2-electrode setup was used with $\mathrm{Ag} / \mathrm{AgCl}$ wire as the reference.

\subsection{Optical monitoring.}

The UME was positioned in a drop cell mounted on a thin glass slide (1mm thickness) on top of an inverted microscope (Olympus IX71) equipped with a long working distance objective ( $x 60, N A=0.7)$. This assembly allows focusing on the apex of a working UME positioned far $(>0.5 \mathrm{~mm})$ from the glass slide. The apex of the UME was then observed under dark field illumination through a dark field condenser using a $100 \mathrm{~W}$ halogen lamp (ULH100L-3 from Olympus). Images were acquired with a CCD Camera Andorlxon 897 at rate up to 30 frames per second.

\subsection{SEM}

The images were recorded using a SEM-FEG from Zeiss (Zeiss SUPRA 40). 


\section{Results and discussion}

\subsection{Principle of the NPs electrosynthesis}

The local synthesis of NPs uses a sacrificial disk, Au or Ag, ultramicroelectrode (UME) in an electrolytic solution containing $1 \mathrm{mM}$ of a reversible electron donor Fe(II) (see Fig. 1), which is, in order of decreasing reducing strength or of increasing $\mathrm{E}^{\circ}$ values, either, ferrocenemethanol $(\mathrm{FcMeOH})$, $\mathrm{Fe}^{2+}$, or iron tris-dipyridyl $\left(\mathrm{Fe}(\mathrm{bpy})_{3}{ }^{2+}\right)$. At $\mathrm{t}=0$, the $\mathrm{UME}$ is polarized at a sufficiently positive potential, $E_{U M E}$, relative to all components (with $\mathrm{E}_{\mathrm{UME}}>\mathrm{E}^{\circ}{ }_{\mathrm{M}}$ and $\mathrm{E}^{\circ}{ }_{\mathrm{Fe}(\mathrm{II})}$, which are respectively the standard redox potential of the $\mathrm{M}^{\mathrm{n}+} / \mathrm{M}$ and $\mathrm{Fe}(\mathrm{III}) / \mathrm{Fe}(\mathrm{II})$ couples (see Scheme 1), such as both the electron donor and the UME material are oxidized. Typically, $E_{U M E}=1.2 \mathrm{~V}$ vs $\mathrm{Ag} / \mathrm{AgCl}$ for the $\mathrm{Au} U \mathrm{UME}$ or $0.7 \mathrm{~V}$ vs $\mathrm{Ag} / \mathrm{AgCl}$ for the $\mathrm{Ag} U \mathrm{UME}$. On one hand, the electron donor is oxidized into its $\mathrm{Fe}(\mathrm{III})$ counterpart at the UME surface. Owing to its micrometric dimension, a steady-state mass transfer by diffusion of $\mathrm{Fe}$ (II) from the bulk solution to the UME is established in a relatively short time (of the order of $a^{2} / \mathrm{D}$, with $a$ the UME radius and $\mathrm{D}$ the $\mathrm{Fe}(\mathrm{II})$ diffusion coefficient). Typically for the $25 \mu \mathrm{m}$ diameter UME and for $\mathrm{t}>5-10 \mathrm{~s}$, the UME is producing a steady state hemispherical concentration gradient of $\mathrm{Fe}(\mathrm{III})$ and $\mathrm{Fe}(\mathrm{II})$ within its diffusion layer, expanding approximately over a distance of $10 a$.

On the other hand, by the oxidation of the sacrificial UME (dissolution), ${ }^{34}$ a concentration gradient of $\mathrm{M}^{\mathrm{n}+}$ ions $\left(\mathrm{AuCl}_{4}{ }^{-}\right.$or $\left.\mathrm{Ag}^{+}\right)$is generated in its diffusion layer, as for the $\mathrm{Fe}(\mathrm{II}) / \mathrm{Fe}(\mathrm{III})$ counterparts. This reaction serves to produce in large excess, compared to the $\mathrm{Fe}(\mathrm{II})$ species, the $\mathrm{M}^{\mathrm{n}+}$ precursors of the metallic NPs that are intended to be formed in solution in the diffusion layer of the UME. The flux of $\mathrm{M}^{\mathrm{n}+}$ produced is controlled by the UME current, $i_{\mathrm{UME}}$, while the time evolution of $i_{\mathrm{UME}}$ is recorded (chronoamperometry). Examples of such chronoamperograms, CAs, are presented in ESI (Figs. S1 and S2) for the different electron donors and UME couples investigated. The UME current reaches rapidly, within $<2-3 \mathrm{~s}$, a steady-state value ensuring the UME is producing a steadystate concentration profile of the $\mathrm{M}^{\mathrm{n}+}$ ions. As will be detailed later, the synthetic procedure for both UME materials is set to a same flux $f$ of metallic precursors estimated from the UME steady-state current, $i_{\mathrm{UME}}$, through:

$f=i_{\mathrm{UME}} / n \mathrm{~F} \pi a^{2}$

with $\mathrm{F}$ the Faraday constant, $n=3$ for the production of $\mathrm{AuCl}_{4}^{-}$ $n=1$ for $\mathrm{Ag}^{+}$, and typically $f \approx 5 \mu \mathrm{mol} . \mathrm{cm}^{-2} \cdot \mathrm{s}^{-1}$. Similarly to the $\mathrm{Fe}$ (II) and $\mathrm{Fe}$ (III) species, under these conditions the UME dissolution generates at its surface $60 \mathrm{mM}$ of $\mathrm{M}^{\mathrm{nt}}$ which, by diffusion towards the bulk, yield local $\left[\mathrm{M}^{\mathrm{nt}}\right]$ between 26 and $3 \mathrm{mM}$ from 12 to $100 \mu \mathrm{m}$ from the UME surface.

The condition of the UME polarization then imposes a quasi steady-state control of the spatial concentration of all reactants, $\mathrm{Fe}(\mathrm{II}), \mathrm{Fe}(\mathrm{III})$ and $\mathrm{M}^{\mathrm{n}+}$ within the ca. $100 \mu \mathrm{m}$ of the UME diffusion layer and conditions of NPs synthesis under excess of $\mathrm{M}^{\mathrm{nt}}$ compared to the reducer/oxidant.

\subsection{Reversible redox mediation of NPs growth.}

The electron donors chosen to mediate the production of $M$ NPs are reducers from reversible redox couples, here $\mathrm{Fe}(\mathrm{II}) / \mathrm{Fe}$ (III) whose $\mathrm{E}^{\circ}$ values, modulated by ligands, were chosen to engage the reduction of the corresponding electrogenerated $\mathrm{M}^{\mathrm{n}+}$ ions, to yield either $\mathrm{Au}(2,3)$ or $\mathrm{Ag}(4,5)$ : $\mathrm{AuCl}_{4}^{-}+3 \mathrm{Fe}^{2+} \rightarrow \mathrm{Au}^{0}+3 \mathrm{Fe}^{3+}+4 \mathrm{Cl}^{-}$

$\mathrm{AuCl}_{4}^{-}+3 \mathrm{Fe}(\mathrm{bpy})_{3}^{2+} \rightleftarrows \mathrm{Au}^{0}+3 \mathrm{Fe}(\mathrm{bpy})_{3}^{3+}+4 \mathrm{Cl}^{-}$

$\mathrm{Ag}^{+}+\mathrm{FCMeOH} \rightarrow \mathrm{Ag}^{0}+\mathrm{FCMeOH}^{+}$

$\mathrm{Ag}^{+}+\mathrm{Fe}^{2+} \rightleftarrows \mathrm{Ag}^{0}+\mathrm{Fe}^{3+}$

The reversibility of the redox transformation of the $\mathrm{Fe}(\mathrm{II}) / \mathrm{Fe}$ (III) couple is intended to induce physical or chemical control over the NP synthesis: spatial confinement, chemical control of the redissolution process and of the growth kinetics. The latter two chemical controls result particularly from the driving force of the $\mathrm{M}^{\mathrm{n}+}$ reduction, $\Delta \mathrm{G}^{0}=-n \mathrm{~F} \Delta \mathrm{E}^{\circ}$, with $\Delta \mathrm{E}^{\circ}=\mathrm{E}^{\circ}{ }_{\mathrm{M}}$

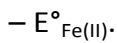

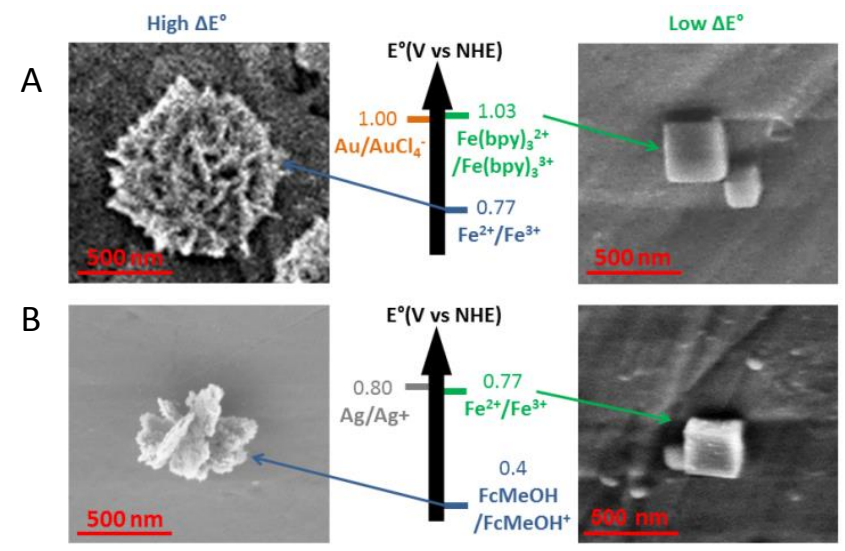

Fig. 1 SEM images of electrogenerated (A) Au and (B) Ag nanoflowers or nanocubes in (A) a $0.1 \mathrm{M} \mathrm{KCl}$ aqueous solution containing $1 \mathrm{mM} \mathrm{Fe}^{2+}$ or $\mathrm{Fe}(\mathrm{bpy})_{3}{ }^{2+}$ by applying $\mathrm{E}_{\mathrm{UME}}=$ $1.2 \mathrm{~V}$ vs $\mathrm{Ag} / \mathrm{AgCl}$ or $(\mathrm{B})$ a $0.05 \mathrm{M} \mathrm{KPF}_{6}$ aqueous solution containing $1 \mathrm{mM} \mathrm{Fe}^{2+}$ or $\mathrm{FcMeOH}$ by applying $\mathrm{E}_{\mathrm{UME}}=0.7 \mathrm{~V} \mathrm{vs} \mathrm{Ag} / \mathrm{AgCl}$. Reducers and their redox potentials compared to those of $\mathrm{Ag}$ and $\mathrm{Au}$ species ${ }^{35}$ are also given.

\subsubsection{Spatial confinement of the NP formation}

First, the mass transfer to and from the UME provides a spatial confinement over the synthesis. As the $\mathrm{Fe}$ (II) oxidation at the UME is mass-transfer limited, the UME surface is devoid of $\mathrm{Fe}(\mathrm{II})$, pushing the $\mathrm{M}^{\mathrm{n}+}$ reduction and therefore the metal formation toward the solution: it prevents the immediate redeposition of the metal on the UME and ensures the production of metallic NPs in a range of 10 to $100 \mu \mathrm{m}$ from the UME surface. This range is compatible with the resolution of the dark field optical microscopy used to monitor, in situ, the electrosynthetic process in neighboring regions of the UME. Examples of videos showing the change in optical densities in these regions under different electrosynthesis conditions are provided in videos (videos SV1 and SV2 for Au UMEs with $\mathrm{Fe}^{2+}$ or $\mathrm{Fe}(\mathrm{bpy})_{3}{ }^{2+}$ as reducer, respectively, $\mathrm{E}_{\mathrm{UME}}=1.2 \mathrm{~V} \mathrm{vs} \mathrm{Ag} / \mathrm{AgCl}$; video SV3 for $\mathrm{Ag} U \mathrm{UME}, \mathrm{E}_{\mathrm{UME}}=0.7 \mathrm{~V}$ vs $\mathrm{Ag} / \mathrm{AgCl}$, in a $\mathrm{FcMeOH}$ solution; the video for the $\mathrm{Ag}$ UME in the presence of $\mathrm{Fe}^{2+}$ is available elsewhere ${ }^{33}$ ).

Immediately after the onset of the UME anodic polarization, at the beginning of all the videos, light-scattering features, 
animated by Brownian motion, appear in solution. As shown in Figs. $2 A$ and $B$ extracted from the videos taken during the $A u$ UME oxidation, these bright features are distributed around the UME within a hemispherical reaction layer of $80 \pm 20 \mu \mathrm{m}$ in the presence of $\mathrm{Fe}^{2+}$ or $40 \pm 15 \mu \mathrm{m}$ for $\mathrm{Fe}(\mathrm{bpy})_{3}{ }^{2+}$. It suggests that these bright features are Au NPs, generated in solution from the electrochemically driven mass transfer of the metal precursor and of the reversible reducer. Similar behaviors are observed during the anodic dissolution of $\mathrm{Ag} U \mathrm{UE}$ in the presence of either $\mathrm{Fe}^{2+}$ or $\mathrm{FcMeOH}$ : Brownian bright features attributed to Ag NPs appear within a reaction layer of 80 $100 \mu \mathrm{m}$.

The presence of metallic NPs in the solution is also confirmed in situ from the UME current, $i_{\mathrm{UME}}$. Indeed, if metal NPs are formed in solution, on their diffusive travel back to the UME surface, they will also be dissolved by oxidation upon collision with the anodically polarized UME. Such reactive NP-UME collisions, known as destructive electrochemical nanoimpacts, ${ }^{36,37}$ are indeed detected in the UME current response as stochastic oxidative short current spikes (see Figs. S2C and S3 -red curve- in ESI), complementing the light scattering observation. ${ }^{20}$

\subsubsection{Shaping the NP through the reduction driving force.}

The presence of the oxidizing Fe(III) counterpart in the UME diffusion layer provides a further chemical feedback over the NPs synthesis from their possible redissolution depending on the occurrence of the backward oxidation (see backward reactions 3 and 5). It is an interesting feature for shapecontrolled NPs synthesis.

As NPs are detected over $100 \mu \mathrm{m}$ from the UME metallic disk, ex situ SEM images of the body of the UME, and particularly of the insulating glass surrounding the UME disk, have been recorded at the end of each electrosynthetic procedure. In all cases NPs were detected confirming the in situ detection of light-scatterers. The ex situ images particularly exemplify the role of the driving force of the $M^{n+}$ reduction on the final NP shape and size.

For the Au UME, using the stronger reducer, $\mathrm{Fe}^{2+}$, gold fractal nanoflowers with an apparent mean size of $680 \mathrm{~nm}$ were obtained (AuNFs; Figs. 1A left and S1A in ESI), in agreement with what was found recently in classical colloidal syntheses from $\mathrm{AuCl}_{4}{ }^{-}$and $\mathrm{Fe}^{2+} \cdot{ }^{25}$ If $\mathrm{Fe}^{2+}$ is replaced by the less reducing $\mathrm{Fe}(\mathrm{bpy})_{3}{ }^{2+}$, cubic NPs are obtained with an average edge length of 250nm (AuNCs; Figs. $1 \mathrm{~A}$ right and S1B in ESI). The shape preference of this new synthetic route of nanocubes, associated with a smaller NP size evidences the control of the NPs growth from the driving force of the metallic salt reduction: compare $\Delta \mathrm{E}_{\mathrm{AuNF}}^{\circ}=\mathrm{E}_{\mathrm{Au}}^{\circ}-\mathrm{E}_{\mathrm{Fe} 2+}^{\circ}=0.23 \mathrm{~V}$ vs $\Delta \mathrm{E}^{\circ}{ }_{\mathrm{AuNC}}=$ $\mathrm{E}_{\mathrm{Au}}^{\circ}-\mathrm{E}_{\mathrm{Febpy2}+}^{\circ}=-0.03 \mathrm{~V}$ or equivalently $\Delta \mathrm{G}_{\mathrm{AuNF}}^{0}=-n \mathrm{~F} \Delta \mathrm{E}_{\mathrm{AuNF}}^{\circ}=-$ $0.69 \mathrm{eV}$ vs $\Delta \mathrm{G}^{0}{ }_{\mathrm{AuNC}}=0.09 \mathrm{eV}$.

A similar trend is confirmed for Ag NPs produced during the electrodissolution of the $\mathrm{Ag} \mathrm{UME}$ in an aqueous solution containing either $\mathrm{FcMeOH}$ or $\mathrm{Fe}^{2+}$ reducing agents. Using FcMeOH (high driving force, $\Delta G^{0}=-0.4 \mathrm{eV}$ ), fractal shaped AgNPs (AgNFs) with an apparent size of $420 \mathrm{~nm}$ were obtained (Figs. $1 \mathrm{~B}$ left and $\mathrm{S} 2 \mathrm{~A}$ in $\mathrm{ESI}$ ), confirming that highly exergonic $\Delta \mathrm{G}^{\circ}$ produce fractal NPs. For the Ag NP system, $\mathrm{Fe}^{2+}$ is now a milder reducer, with a slightly exergonic driving force $\left(\Delta \mathrm{G}^{0}{ }_{\mathrm{AgNC}}=-\right.$ $0.03 \mathrm{eV}$ ) and again $\mathrm{Ag}$ nanocubes (AgNCs) are preferentially produced with a mean edge length of 270nm (Fig. S2B in ESI). In agreement with AuNPs, AgNCs are smaller than AgNFs, suggesting that the driving force of the reduction also controls the NP growth rate. Noteworthy, the synthesis of cubic AgNPs in $\mathrm{Fe}^{2+} / \mathrm{Fe}^{3+}$ gradient is consistent with the reported role of $\mathrm{Fe}^{3+}$ oxidative etchant during the chemical synthesis of metallic nanocubes using either $\mathrm{Ag}$ or $\mathrm{Pd}$ ions precursors ${ }^{38}$ or from the reduction of octahedral $\mathrm{AgCl} .{ }^{39}$ Under conditions of reversible growth thermodynamics, the presence of $\mathrm{Fe}^{3+}$ ions allows kinetics control and preferential facet growth. At higher driving force, as for the formation of AuNPs by $\mathrm{Fe}^{2+}$, the NPs etching by electrogenerated $\mathrm{Fe}^{3+}$ is thermodynamically unlikely, yielding a fractal growth from multiple seeds. Owing to the immediate observation of scattering features in the UME diffusion layer, the NPs are grown from the coalescence of highly mobile and concentrated seeds, most likely the small metal nuclei involved in coalescence-based growth mechanisms. ${ }^{2,4,40}$

In the most endergonic reduction case, when Au NCs are formed by reduction by $\mathrm{Fe}(\mathrm{bpy})_{3}{ }^{2+}$, a slow redissolution of the NPs could be monitored in situ. In video SV2 (SI), the scattering features, which appeared during the UME polarization progressively disappear after the polarization has been halted, which is not the case with $\mathrm{Fe}^{2+}$ or in any of the Ag NP electrosyntheses. This progressive redissolution of AuNPs by $\mathrm{Fe}(\mathrm{bpy}){ }_{3}{ }^{3+}$ generated at the UME (explained by the occurrence of the backward reaction 3 ) can explain also why the reaction layer surrounding the UME (observed by dark field) is smaller than for all other cases.

\subsection{In situ monitoring of the NP growth dynamics.}

\subsubsection{Average NP sizing from individual NP motion.}

The previous section suggests how the $M^{\text {n+ }}$ salt reduction driving force affects the NP shape and controls the NP size. Owing to the fast growth observed (>400nm in less than 10s), assessing the growth dynamics requires in situ monitoring. We use the ability of the dark field optical microscopy to dynamically localize the position of individual NPs while synthesized. The reactive trajectories of many individual NPs were extracted from the videos, allowing analyzing the mean square displacement (MSD) of these individual NPs during their electrosynthesis (Section 1 in ESI).

Examples of temporal MSDs were plotted in a log-log scale versus the time lag, $t_{\text {lag }}$ (time elapsed since the NP has been first detected in the field of view and tracked) in Figs. $2 C$ and $D$, and S4A and B in ESI for, respectively, the electrosynthesis of AuNFs, AuNCs, AgNFs and AgNCs. The linear MSD-time variation (unity slope in the log-log plot) observed for the different MSDs at the earliest times $(t<1 s)$ attests to a Brownian motion for which the MSD-time slope corresponds to $4 D_{N P}$, where $D_{N P}$ is the average diffusion coefficient of the tracked NP during its trajectory. This allows estimating the average hydrodynamic radius of individual NPs, $R_{p, M S D}$, from the Stokes-Einstein relationship, $D_{N P}=k_{B} T / 6 \pi \eta R_{p, M S D}$, with $k_{B}$ 
the Boltzmann constant, $T$ the temperature and $\eta$ the solvent viscosity. The analysis of the MSDs yields a distribution of the $N P$ apparent $R_{p, M S D}$ (Figs. $2 E$ and $F, S 4 C$ and $D$ in ESI, for, respectively, AuNFs, AuNCs, AgNFs and AgNCs) that was compared to the apparent radius deduced from the SEM images, $R_{p, S E M}$ (insets in the same Figs.): for NFs $R_{p, S E M}$ was estimated as the half of the NF size, while for NCS $R_{p, S E M}$ was estimated from the nanocubes edge length, $l$, with $R_{p, S E M}=/(3 /(4 \pi))^{1 / 3}$. The mean values obtained from each distribution, $R_{p, M S D \text {,mean }}$ and $R_{p, S E M}$,mean, and for the different electrosynthesis procedures are listed in Table 1 . The distributions of $R_{p, S E M}$ are comparable to those of $R_{p, M S D}$ for AgNFs and AgNCs, both in terms of mean value and size dispersion.
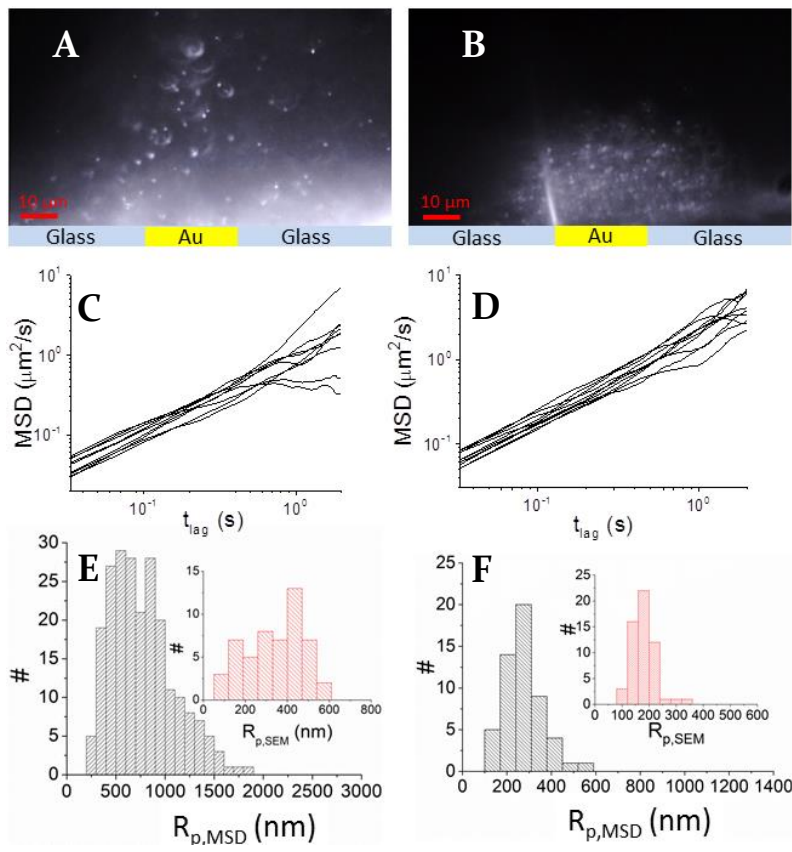

Fig. 2 A,B) Dark field optical images extracted from videos SV1 and SV2 in the region of the apex of an $\mathrm{Au} U \mathrm{UME}$, taken $\sim 5 \mathrm{~s}$ after the application of $\mathrm{E}_{\mathrm{UME}}=1.2 \mathrm{~V} \mathrm{vs} \mathrm{Ag} / \mathrm{AgCl}$ in $0.1 \mathrm{M}$ $\mathrm{KCl}(\mathrm{aq})$ in the presence of $1 \mathrm{mM}$ of $\mathrm{A}) \mathrm{Fe}^{2+}$ or B) $\mathrm{Fe}(\mathrm{bpy})_{3}{ }^{2+}$. C,D) MSD analyses of individual AuNFs and AuNCs trajectories, respectively. E, F) Distributions of AuNFs and AuNCs hydrodynamic radius $\left(R_{p, M S D}\right)$, respectively, from MSD analysis of individual $2 D$ trajectories. Insets: distributions of the radius inferred from SEM images (Fig. S1 A and $B$ in ESI).

For AuNFs, $R_{p, M S D, \text { mean }}$ is significantly higher than $R_{p, S E M \text {, mean }}$ (Fig. $2 E)$. The presence of large AuNFs $\left(R_{p, M S D}>250 n m\right)$, inferred from the MSD analysis, was also confirmed from their optical sizing directly from the images in video SV1. Indeed, when particles become larger than the diffraction limit, their optically resolved radius, $R_{p, o p t}$, was estimated from the fullwidth at half maximum, FWHM, of the optical intensity profile of their corresponding scattering feature $\left(R_{p, o p t}=1 / 2 F W H M\right.$, as shown in Fig. S5A and B in ESI). For two examples of large Au NFs presented in Fig. S5B in ESI, the optically inferred $R_{p, o p t}$ ( 840 and $330 \mathrm{~nm}$ ) are in good agreement with the corresponding $R_{p, M S D}$ extracted from the MSD (880 and 370 $\mathrm{nm})$. The higher values of AuNFs size estimated optically likely correspond to NPs agglomerates, which are more prone to sedimentation rather than bonding to the UME and cannot be detected by SEM analysis. The hypothesis of agglomeration phenomenon is further supported by the higher attractive van der Waals interactions for bigger NPs, ${ }^{4}$ as well as the higher Hamaker constant for Au than for Ag. ${ }^{11}$

The MSD analysis for AuNCs performed only during the growth phase provides higher $R_{p, M S D}\left(R_{p, M S D, \text { mean }} \approx 270 \mathrm{~nm}\right)$ than those observed by $\operatorname{SEM}\left(R_{p, S E M}\right.$,mean $\left.\approx 170 \mathrm{~nm}\right)$. This can be explained by the partial dissolution of the NPs after the end of the electrosynthesis, as shown from video SV2.

Overall, the MSD analyses clearly evidence, in good agreement with the SEM characterizations, that $R_{p, A u N F}>R_{p, A u N C}$ and $R_{p, A g N F}>R_{p, A g N C}$. It follows the magnitude of the $M^{n+}$ ion reduction driving force of the different electrosynthesis procedures $\left(\Delta G^{0}{ }_{A u N F}<\Delta G^{0}{ }_{A u N C}\right.$ and $\Delta G^{0}{ }_{A g N F}<\Delta G^{0}{ }_{A g N C}$, as shown in Fig. 1 and Table 1 ).

\subsubsection{Inspecting the driving force influence on single NPs growth} dynamics.

If in average the size copped by both in situ and ex situ NP sizing approaches are correlated, a more detailed analysis of the MSD curves allows to account for the growth dynamics of the NPs according to the methodology previously described. ${ }^{33}$ Briefly, for time-dependent process such as NP growth, each growing NP is characterized by a time-dependent diffusion coefficient, $D_{N P}(t)$. Thus, from the Stokes-Einstein relationship, it is possible to extract the time-dependence of the hydrodynamic radius $R_{p, M S D}(t)$ of a given NP by segmenting its trajectory over discrete time lapses. Typical evolutions of $R_{p, M S D}(t)$ are shown for the different syntheses in Figs. 3A and $B$ and $\mathrm{S} 6 \mathrm{~A}$ and $\mathrm{B}$ in ESI (black traces) for AuNFs, AuNCs, AgNFs and AgNCs, respectively. From such curves, the experimental growth rates of individual NPs were determined.

The apparent NP size increase with the reduction driving force suggests a kinetic control over the NP growth, likely by the reduction reaction, rather than a diffusion controlled process. A simple kinetic model using a first order kinetic growth is proposed in Section 2 of the ESI, it suggests a linear evolution of $R_{p, M S D}(t)$ with time:

$\mathrm{R}_{\mathrm{p}, \mathrm{MSD}}(\mathrm{t})=\mathrm{R}_{\mathrm{p} 0, M S D}+\kappa \mathrm{t}$

where $R_{p 0, M S D}$ is the radius of a given individual NP at the beginning of its tracking (taken as $t=0$ in equation 6 ) and $\mathrm{K}$ is its individual apparent growth rate constant (in $\mu \mathrm{m} / \mathrm{s}$ ).

Individual NP growth rates were then extracted by fitting the experimental size-transients, $R_{p, M S D}(t)$, obtained from each NP trajectory, by (6) (blue traces in Figs. $3 A$ and $B$ and $S 6 A$ and $B$ in ESI for AuNFs, AuNCs, AgNFs and AgNCs, respectively). For each synthesis procedure a distribution of individual NP growth rate constants, $\kappa$, is then produced (Figs. $3 C$ and $D$ and S6C and D (ESI) for AuNFs, AuNCs, AgNFs and AgNCs, respectively) from which median growth rates values $\left(K_{m}\right)$ with associated standard errors are extracted from the cumulative frequency of the individual growth rates, as explained in Fig. S7 (ESI), and reported in Table 1.

The growth of the NPs during the different synthetic procedures can then be discussed at the single and ensemble NP levels. 

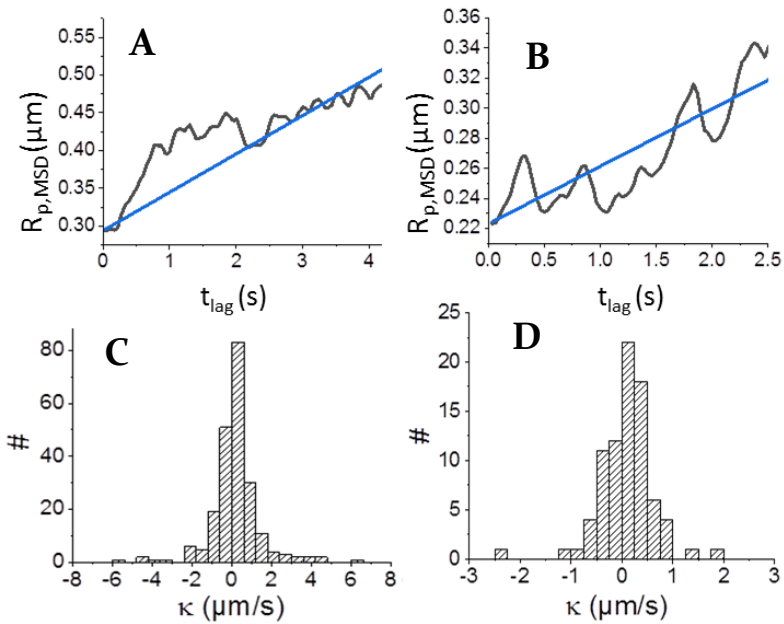

Fig. $3 \mathrm{~A}, \mathrm{~B})$ Examples of experimental single Au NPs instantaneous radius evolution with time (black); fit by A) $K_{\text {AunF }}=0.16 \mu \mathrm{m} / \mathrm{s}$ and $B$ ) $K_{\text {Aunc }}=0.12 \mu \mathrm{m} / \mathrm{s}$ (blue). C, D) Distribution of $\mathrm{K}_{\mathrm{AuNF}}$ extracted from video SV1 and $\mathrm{K}_{\text {AunC }}$ extracted from the first $7 \mathrm{~s}$ of video SV2 and another video in which the potential was applied continuously (> 70 images), respectively. Mean $\mathrm{k}$ and associated standard deviation are given in Table 1.

At the single entity level, the individual NP growth rate, $\kappa$, distributions are widely spread over the median value, which is due to propagation of errors intrinsically associated to MSD analysis. However different trends can be suggested from these distributions. First, the $\kappa$ values for each NP whatever the synthesis procedure cannot be correlated to the NP initial size, $R_{\mathrm{p} 0, \mathrm{MSD}}$, supporting the kinetic limitation assumption. Then, the $\kappa$ distributions suggests an overall growth $(\kappa>0)$ of the NP during the UME polarization and therefore the electrogeneration of $\mathrm{M}^{\mathrm{n}+}$ ions for the majority of the tracked NPs and whatever the synthesis procedure and therefore whatever the NP shape. Except for the AuNCs, the NP size does not significantly change few seconds after the UME polarization is halted, suggesting the growth is driven by the continuous income of metal precursors from the electrode. In the case of the AuNCs, video SV2 suggests that AuNCs redissolve in solution when the electrogeneration of $\mathrm{Au}$ precursors is halted.

This redissolution can be resolved using the same methodology. The MSD analysis of the full video SV2 (SI) comprising both the period of UME polarization (first $7 \mathrm{~s}$ of video SV2) followed by the period without polarization (last $8 \mathrm{~s}$ of video SV2) may reveal, in Fig. S8B (ESI), a bimodal population of NPs with a dominant population of growing $(\kappa>0)$ NPs and another population of dissolving NPs $(\kappa<0)$. The situation is exalted when analyzing separately the trajectories during the UME polarization (Figs. 3D and S8C in ESI) or after it (Fig. S8D in ESI). If during the polarization the $\kappa$-distribution suggests an overall growth of NPs, after the polarization was halted, the whole $\kappa$-distribution is shifted toward negative $\kappa$ values, allowing here too a means to quantify the NP dissolution kinetics.

At an ensemble NP level, the median growth rate constants $\kappa_{\mathrm{m}}$ extracted from in situ and individual NP behaviors during all electrosyntheses decrease in the following order $\kappa_{m, A u N F}>\kappa_{m, A u N c}>\kappa_{m, A g N F}>\kappa_{m, A g N c}$ (Table 1 ). It confirms the same trend observed when estimating the NP sizes ex situ at the end of each synthesis and also supports that the higher the growth rate $\kappa$, the larger the NP size at the end of the synthesis.

Moreover, for AuNFs, AgNFs and AgNCs, this trend parallels the $\mathrm{M}^{\mathrm{n}+}$ ion reduction driving force variations: the more exergonic the reduction, the faster the NP growth. In the case of a kinetic control by the $\mathrm{M}^{\mathrm{n}+}$ ion reduction, one anticipates $\mathrm{K}$ is proportional to the local concentration, $\left[\mathrm{M}^{\mathrm{n}+}\right]$, and therefore to the $\mathrm{M}^{\mathrm{n}+}$ generated flux, $\mathrm{f}$, given by the UME current, so that $\kappa_{\mathrm{m}}$ scales as $i_{\mathrm{UME}} / n$. As indicated in Section 2.1 (ESI), the different syntheses were produced at approximately constant $\mathrm{M}^{\mathrm{n}+}$ ions flux (meaning constant $i_{\mathrm{UME}} / n$ ). In the proposed simple first-order reaction rate framework, the variation of the NP growth with the reduction driving force may be rationalized by an activation-driving force relationship:

$\kappa_{m}=\mathrm{e}^{\frac{\alpha \mathrm{F}}{\mathrm{RT}} \Delta \mathrm{G}^{\circ}}$

where $\alpha$ corresponds to the apparent transfer coefficient of the overall process. This activation-driving force relationship is presented as the line in Fig. $4 \mathrm{~A}$ gathering the experimental variations of the different NP growth rates, $\kappa_{m}$, with $\Delta G^{0}$.

For the three AgNFs, AgNCs and AuNFs, a linear log $\kappa_{m}-\Delta G^{0}$ trend holds reasonably with a rather low value of $\alpha=0.06$. Such moderate effect of the driving force on the NP growth rates suggests an overall more complex growth mechanism. However, the $\mathrm{M}^{\mathrm{n}+}$ reduction contributes to this overall mechanism, which is in line with the in situ X-Ray probing of the speciation of metallic species present in solution during NP synthesis. ${ }^{40}$ Indeed, during the Au NP synthesis from the irreversible citrate reducer, even if metallic Au nuclei, which coalesce into NPs, are formed in the solution, $\mathrm{Au}$ (III) ions prevails in the solution. ${ }^{40 a}$ Our study suggests that this prevalence may be attributed to the kinetically limited reduction of the $\mathrm{Au}(\mathrm{III})$ ion.

\subsubsection{Mechanism for the growth/dissolution process leading to AuNCs.}

Noteworthy, the growth rate for the AuNCs, $\kappa_{m \text {,Aunc, }}$ is significantly above the previously discussed structure-activity trendline. The faster growth rate observed for AuNCs than for AuNFs evidences that the shape is not only controlled by the growth rate. Indeed the re-dissolution of the NPs observed optically strongly suggests that the shape is rather controlled by the dissolution step. ${ }^{42}$ Moreover the voltammetric $i$-E curve recorded during the Au UME dissolution (see Fig. S3 in ESI) shows that the overall $\mathrm{Au}$ metal dissolution is shifted by $\sim 0.14 \pm 0.02 \mathrm{~V}$ toward more anodic potentials when $\mathrm{Fe}(\mathrm{bpy})_{3}{ }^{2+}$ is used instead of $\mathrm{Fe}^{2+}$. This potential difference is rationalized by the electrochemical dissolution of $\mathrm{Au}$ into another reactive $\mathrm{Au}$ ionic species.

The production of $\mathrm{Au}(\mathrm{l})$ species such as $\mathrm{AuCl}_{2}^{-}$has been proposed in aqueous media. ${ }^{43}$ From its tabulated standard potential, $\mathrm{Au}(\mathrm{l})$ is a stronger oxidant than $\mathrm{Au}(\mathrm{III})$ with difference in potential of $E^{\circ}\left(\mathrm{Au} / \mathrm{AuCl}_{2}{ }^{-}\right)-\mathrm{E}^{\circ}\left(\mathrm{Au} / \mathrm{AuCl}_{4}{ }^{-}\right)=0.15 \mathrm{~V}$, in line with the potential shift observed in the voltammetric curve (Fig. S3 in ESI). It is then likely that the presence of $\mathrm{Fe}(\mathrm{bpy})^{2+/ 3+}$ species inhibits the UME dissolution route into 
$A u(I I I)$, in favor of its one-electron dissolution according to equation 8:

$\mathrm{Au}^{0}+2 \mathrm{Cl}^{-} \rightarrow \mathrm{AuCl}_{2}^{-}+1 \mathrm{e}^{-}$
The AuNCs formation by $\mathrm{Fe}(\mathrm{bpy})_{3}{ }^{2+}$ would then rely on the electrogeneration of $\mathrm{AuCl}^{2-}$, producing the AuNCs with a three times higher flux of metallic precursor (see equation $1, n=1$

\begin{tabular}{ccc|cccc}
\hline UME & Reducer & $\begin{array}{c}\Delta \mathrm{G}^{\circ} \\
(\mathrm{eV})\end{array}$ & $\mathrm{NP}$ & $\begin{array}{c}\mathrm{R}_{\mathrm{p}, \mathrm{SEM}, \text { mean }} \\
(\mathrm{nm})\end{array}$ & $\begin{array}{c}\mathrm{R}_{\mathrm{p}, \mathrm{MSD}, \text { mean }} \\
(\mathrm{nm})\end{array}$ & $\begin{array}{c}\mathrm{K}_{\mathrm{m}} \\
(\mu \mathrm{m} / \mathrm{s})\end{array}$ \\
\hline $\mathrm{Au}$ & $\mathrm{Fe}^{2+}$ & -0.69 & AuNF & $340 \pm 130$ & $700 \pm 250$ & $0.18 \pm 0.03$ \\
& $\mathrm{Fe}(\mathrm{bpy})_{3}{ }^{2+}$ & 0.09 & AuNC & $170 \pm 30$ & $270 \pm 90$ & $0.13 \pm 0.06$ \\
& & $-0.12)^{\mathrm{a}}$ & & & & \\
\hline $\mathrm{Ag}$ & $\mathrm{FcMeOH}$ & -0.4 & AgNF & $200 \pm 50$ & $210 \pm 20$ & $0.08 \pm 0.015$ \\
& $\mathrm{Fe}^{2+}$ & -0.03 & AgNC & $170 \pm 50$ & $120 \pm 60$ & $0.04 \pm 0.015$
\end{tabular}

Table 1. $R_{p, S E M, m e a n}, R_{p, M S D}$,mean and median growth rate constant $\mathrm{K}_{m}$ as a function of the metal and the reducer used for the NPs syntheses. ${ }^{\mathrm{a}} \mathrm{For}$ Fe(bpy) ${ }_{3}{ }^{2+}$ the value in brackets considers $\mathrm{AuCl}_{2}^{-}$as the Au NP precursor, rather than $\mathrm{AuCl}_{4}{ }^{-}$.

$$
\text { A }
$$

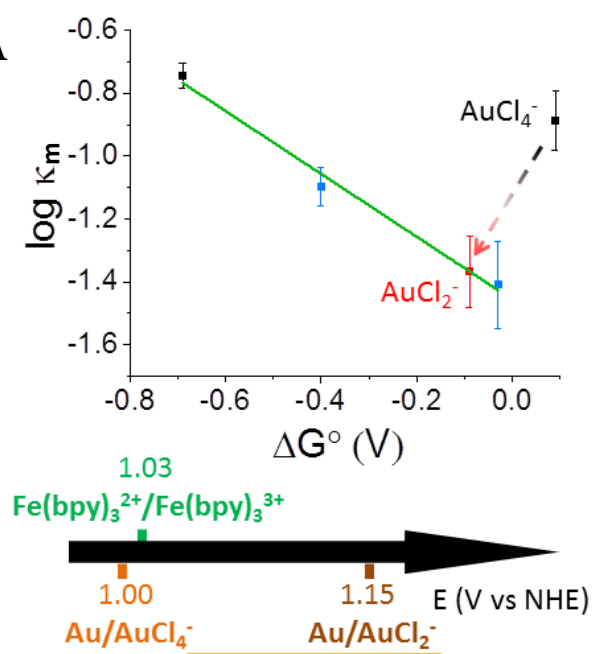

B
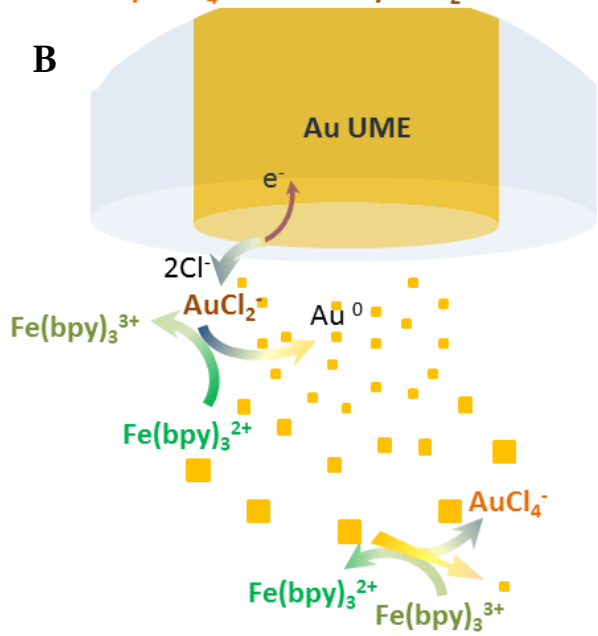

Fig. 4 A) $\log \kappa_{m}$ for the different NP synthetic procedures as a function of the driving force for the reduction of $\mathrm{M}^{\mathrm{n}+}$ by the reducer; $\mathbf{\square}$ : Au NPs, $\square$ : Ag NPs and $\mathbf{\square}$ : AuNCs according to the mechanism proposed in $B$ ). The slope of the green line yields an apparent value of $\alpha=0.06$.

The formation of AuNCs in solution would then result (Fig. 4B) from the 1-electron reduction of $\mathrm{AuCl}_{2}{ }^{-}$by $\mathrm{Fe}(\mathrm{bpy})_{3}{ }_{3}^{2+}$, with now a more exergonic driving force $\Delta \mathrm{G}^{0}=-0.12 \mathrm{eV}\left(\Delta \mathrm{E}^{\circ}=\mathrm{E}^{\circ}{ }_{\mathrm{M}}-\mathrm{E}_{\mathrm{Fe}}^{\circ}(\mathrm{II})\right.$ $=0.12 \mathrm{~V}$ ):

$\mathrm{AuCl}_{2}^{-}+\mathrm{Fe}(\text { bpy })_{3}^{2+} \rightarrow \mathrm{Au}^{0}+\mathrm{Fe}(\text { bpy })_{3}^{3+}+2 \mathrm{Cl}^{-}$ rather than $n=3$ in the presence of $\mathrm{Fe}^{2+}$ ). Noteworthy, taking into account a correction factor of 3 owing to the $\mathrm{Au}(\mathrm{I})$ precursor flux for the AuNCs growth rate constant, $\mathrm{km}$, and the modification of the $\Delta G^{0}$ value, the corrected point for the AuNCs electrosynthesis now falls within the same trendline followed for the other synthesis processes (Fig. 4B). Together with the voltammetric curve, this further supports a mechanism implying the electrogeneration of $A u(I)$ species.

Finally, the position of the potentials of the different redox systems suggests that the strong oxidant $\mathrm{Fe}(\mathrm{bpy})_{3}{ }^{3+}$, also generated at the UME during its polarization, is able to etch $\mathrm{Au}$ by formation of $\mathrm{AuCl}_{4}{ }^{-}\left(\Delta \mathrm{G}^{0}{ }_{\text {diss }}=-0.09 \mathrm{eV}\right.$, backward reaction 3$)$. This reaction, depicted in Fig. $4 \mathrm{~B}$ is most likely responsible for the observed AuNCs dissolution after the UME polarization was halted.

\section{Conclusions}

The electrosynthesis of colloidal Au and Ag NPs is performed from the anodic dissolution of sacrificial $\mathrm{Au}$ or $\mathrm{Ag} U \mathrm{UMEs}$, without ligands in an aqueous solution containing various reversible redox reducers based on Fe(II) complexes. This electrochemical procedure allows a controlled triggering of the NP generation, which is monitored either ex situ by SEM or in situ by dark field optical microscopy. The shape of the NPs is related to the driving force given by $\Delta \mathrm{E}^{\circ}$ between the redox reducer and the metal ion precursor. Indeed, SEM images reveal that higher driving forces lead to fractal NPs whereas lower ones lead to well-defined nanocubes, suggesting a control of the NP formation by the reductive growth/oxidative etching thermodynamics.

In situ optical tracking of the trajectories of single NPs allows analyzing the growth process of the individual NPs inside the diffusion layer of the UME for the different electrosynthesis procedures. The mean hydrodynamic radius extracted from the in situ tracking is in good agreement with the radius found by SEM for silver NPs. Thanks to the in situ visualization, more complicated growth processes can also be observed. For example the mechanism for AuNCs formation based on a reduction/dissolution process is highlighted. A deeper analysis of the individual NPs growth allows estimating the growth rate 
constants $\mathrm{k}$ for each process and a structure-activity relationship between logk and $\Delta \mathrm{G}^{0}$ is found, attesting a kinetically limited growth. The extension of such relationship to other electron donors (irreversible included) should be promising for both size and shape control rationalization in NP synthesis. Based on such relationship and electrochemical observations, it was actually proposed a new synthetic route for the formation of AuNCs, which is based on the reduction of $\mathrm{AuCl}_{2}^{-}$rather than $\mathrm{AuCl}_{4}^{-}$. The accuracy of high resolution optical microscopy analysis opens new routes to decipher in situ the dynamics and the mechanistic investigation and therefore in situ structure activity relationships for the formation of various other nanomaterials.

\section{Conflicts of interest}

There are no conflicts to declare.

\section{Acknowledgements}

This work was financially supported by Labex MiChem, part of the French state funds managed by the Agence Nationale pour la Recherche, ANR, within the Investissement d'Avenir program under reference ANR-11-IDEX-004-02, by the Emergence call from Université de Paris within the Investissement d'Avenir program under reference ANR-18IDEX-0001, CNRS, Paris Diderot University.

\section{Reference}

1 R. Narayanan and M. A. El-Sayed, Nano Lett. 2004, 4, 13431348.

2 E. E. Finney and R. G. Finke, J. Colloid Interface Sci. 2008, 317, 351-374.

3 N. T. K. Thanh, N. Maclean and S. Mahiddine, Chem. Rev. 2014, 114, 7610-7630.

4 J. Polte, Cryst Eng. Comm. 2015, 17, 6809-6830.

5 K. An and G. A. Somorjai, Chem CatChem 2012, 4, 1512-1524.

6 a) V. Gorshkov, A. Zavalov and V. Privman, Langmuir 2009, 25, 7940-7953; b) M. M. Mariscal, J. J. Velazquez-Salazar and M. J. Yacaman, Cryst. Eng. Comm. 2012, 14, 544-549; c) M. Konuk and S. Durukanoglu, Phys. Chem. Chem. Phys. 2016, 18, 1876-1885.

7 H.-G. Liao, K. Niu and H. Zheng, Chem. Comm. 2013, 49, 11720-11727.

8 Y. Xia, Y. Xiong, B. Lim and S. E. Skrabalak, Angew.Chem. Int. Ed. 2008, 48, 60-103.
9 H. Koerner, R. I. MacCuspie, K. Park and R. A. Vaia, Chem. Mater. 2012, 24, 981-995.

10 H. E. M. Hussein, R. J. Maurer, H. Amari, J. J. Peters, L. Meng, R. Beanland, M. E. Newton and J. V. Macpherson, ACS Nano 2018, 12, 7388-7396.

11 a) E. Sutter, P. Sutter, A. V. Tkachenko, R. Krahne, J. de Graaf, M. Arciniegas and L. Manna, Nat. Commun. 2016, 7, 11213; b) K. Ouhenia-Ouadahi, A. Andrieux-Ledier, J. Richardi, P.-A. Albouy, P. Beaunier, P. Sutter, E. Sutter and A. Courty, Chem. Mater. 2016, 28, 4380-4389; c) Q. Chen, H. Cho, K. Manthiram, M. Yoshida, X. Ye and A. P. Alivisatos, ACS Cent. Sci. 2015, 1, 33-39; d) H. M. Zheng, S. A. Claridge, A. M. Minor, A. P. Alivisatos and U. Dahmen, Nano Lett. 2009, 9, 2460-2465; e) M. H. Nielsen, S. Aloni and J. J. De Yoreo, Science 2014, 345, 1158-1162; f) D. S. Li, M. H. Nielsen, J. R. I. Lee, C. Frandsen, J. F. Banfield and J. J. De Yoreo, Science 2012, 336, 1014-1018; g) E. A. Sutter and P. W. Sutter, Nanoscale 2017, 9, 1271-1278.

12 T. Su, Z. L. Wang and Z. Wang, Small 2019, 15, 1900050.

13 M. R. Hauwiller, J. C. Ondry and A. P. Alivisatos, J. Vis. Exp. 2018, 135, 57665.

14 Y. Sun and Y. Wang, Nano Lett. 2011, 11, 4386-4392.

15 E. Sutter, K. Jungjohann, S. Bliznakov, A. Courty, E. Maisonhaute, S. Tenney and P. Sutter, Nat. Comm. 2014, 5, 4946.

16 A. Hutzler, T. Schmutzler, M. P. M. Jank, R. Branscheid, T. Unruh, E. Spiecker and L. Frey, Nano Lett. 2018, 18, 72227229.

17 M. Wang, C. Park and T. J. Woehi, Chem. Mater. 2018, 30, 7727-7736

18 a) S. Sun, M. Gao, G. Lei, H. Zou, J. Ma and C. Z. Huang, Nano Research 2016, 9, 1125-1134; b) Y. Liu and C. Z . Huang, ACS Nano 2013, 7, 11026-11034.

19 a) A. N. Patel, A. Martinez-Marrades, V. Brasiliense, D. Koshelev, M. Besbes, R. Kuszelewicz, C. Combellas, G. Tessier and F. Kanoufi, Nano Lett. 2015, 15, 6454-6463; b) V. Brasiliense, P. Berto, C. Combellas, G. Tessier and F. Kanoufi, J. Am. Chem. Soc. 2016, 138, 3478-3483; c) V. Brasiliense, P. Berto, C. Combellas, G. Tessier and F. Kanoufi, Acc. Chem. Res. 2016, 49, 2049; d) V. Brasiliense, J. Clausmeyer, A. L. Dauphin, J.-M. Noël, P. Berto, G. Tessier, W. Schuhmann and F. Kanoufi, Angew. Chem. Int. Ed. 2017, 56, 10598-10601.

20 R. Xie, C. Batchelor-McAuley, N. Young and R. G. Compton, Nanoscale, 2019, 11, 1720-1727.

21 a) D. A. Robinson, A. M. Kondajji, A. D. Castaneda, R. Dassari, R. M. Crooks and K. J. Stevenson, J. Phys. Chem. Lett. 2016, 7, 2512-2517; b) S. V. Sokolov, K. Tschulik, C. BatchelorMcAuley, K. Jurkschat and R. G. Compton, Anal. Chem. 2015, 87, 10033-10039; c) S. E. Fodsick, M. J. Anderson, E. G. Nettleton and R. M. Crooks, J. Am. Chem. Soc. 2013, 135, 5994-5997.

22 a) C. M. Hill and S. Pan, J. Am. Chem. Soc. 2013, 135, 1725017253; b) Y. Fang, H. Wang, H. Yu, X. Liu, W. Wang, H.-Y. 
Chen and N. J. Tao, Acc. Chem. Res. 2016, 49, 2614-2624; c) C. P. Byers, B. S. Hoener, W. S. Chang, S. Link and C. F. Landes, Nano Lett. 2016, 16, 2314-2321.

23 C. Little, C. Batchelor-McAuley, K. Ngamchuea, C. Lin, N. Young and R. G. Compton, Chem. Open 2018, 7, 370-380.

24 a) K. Wonner, M. V. Evers and K. Tschulik, J. Am. Chem. Soc. 2018, 140, 12658-12661; b) K. Wonner, M. V. Evers and K. Tschulik, Electrochim. Acta 2019, 301, 458-464.

25 J. Djafari, A. Fernández-Lodeiro, D. García-Lojo, J. FernándezLodeiro, B. Rodríguez-González, I. Pastoriza-Santos, J. PérezJuste, J. L. Capelo and C. Lodeiro, ACS Sustain. Chem. Eng. 2019, 7, 8295-8302.

26 A. Atesyan, O. Belhadj, C. Combellas, F. Kanoufi, V. Rouchon and J.-M. Noël, ChemElectroChem 2019, 6, 779-786.

27 G. Mettela and G. U. Kulkarni, Nano Res. 2015, 8, 29252934.

28 A. J. D. Magenau, N. C. Strandwitz, A. Gennaro and K. Matyjaszewski, Science 2011, 332, 81-84.

29 a) L. Rodriguez-Sánchez, M. C. Blanco and M. A. LópezQuintela, J. Phys. Chem. B 2000, 104, 9683-9688; b) G. R. Nasretdinova, R. R. Fazleeva, R. K. Mukhitova, I. R. Nizameev, M. K. Kadirov, A. Y. Ziganshina and V. V. Yanilkin, Electrochem. Commun. 2015, 50, 69-72; c) V. V. Yanilkin, N. V. Nastapova, G. R. Nasretdinova, R. R. Fazleeva and Y. N. Osin, Electrochem. Commun. 2016, 69, 36-40.

30 T. Yousefi, R. Davarkhah, A. N. Golikand, M. H. Mashhadizadeh and A. Abhari, Prog. Nat. Sci. Mater. 2013, 23, 51-54.

31 a) M. T. Reetz and W. Helbig, J. Am. Chem. Soc. 1994, 116, 7401-7402; b) M. T. Reetz and S. A. Quaiser, Angew. Chem. Int. Ed. 1995, 56, 2240-2241; c) N. Vilar-Vidal, M. C. Blanco, M. A. López-Quintela, J. Rivas and C. Serra, J. Phys. Chem. C 2010, 114, 15924-15930; d) B. S. González, M. C. Blanco and M. A. López-Quintela, Nanoscale 2012, 4, 7632-7635; e) C. Fernandez-Blanco, A. Colina, A. Heras, V. Ruiz and J. LopezPalacios, Electrochem. Commun. 2012, 18, 8-11.

32 M. T. Reetz, W. Helbig and S. A. Quaiser, Chem. Mater. 1995, 7, 2227-2228.

33 V. Brasiliense, J.-M. Noël, K. Wonner, K. Tschulik, C. Combellas and F. Kanoufi, ChemElectroChem 2018, 5, 30363043.

34 a) S. Meltzer and D. Mandler, J. Electrochem. Soc. 1995, 142, L82-L84; b) I. Turyan, M. Etienne, D. Mandler and W. Schuhmann, Electroanalysis 2005, 17, 538-542; c) E. Malel, R. Ludwig, L. Gorton and D. Mandler, Chem. Eur. J. 2010, 16 11697-11706.

35 P. Vanýsek, in Electrochemical series in CRC Handbook of Chemistry and Physics, 83rd ed., Ed: D. R. Lide, CRC Press, Boca Raton, 2002, pp 8-21-8-31.

36 a) Y. G. Zhou, N. V. Rees and R. G. Compton, Angew. Chem. Int. Ed. 2011, 50, 4219-421; b) E. J. E. Stuart, N. V. Rees, J. T. Cullen and R. G. Compton, Nanoscale, 2013, 5, 174-177; c) B. Plowman, K. Tschulik, E. Walport, N. Young and R. G. Compton, Nanoscale, 2015, 7, 12361-12364.
37 W. Cheng and R. G. Compton, Trends Anal. Chem. 2014, 58, 79-89.

38 Y. Ma, W. Li, J. Zeng, M. McKiernan, Z. Xie and Y. Xia, J. Mater. Chem. 2010, 20, 3586-3589.

39 S. Zhou, J. Li, K. D. Gilroy, J. Tao, C. Zhu, X. Yang, X. Sun and Y. Xia, ACS Nano 2016, 10, 9861-9870.

40 a) J. Polte, T. T. Ahner, F. Delissen, S. Sokolov, F. Emmerling, A. F. Thünemann and R. Kraehnert, J. Am. Chem. Soc. 2010 132, 1296-1301; b) J. Polte, R. Erler, A. F. Thünemann, S. Sokolov, T. T. Ahner, K. Rademann, F. Emmerling and R. Kraehnert, ACS Nano 2010, 4, 1076-1082.

41 K. Jiang and P. Pinchuk, Nanotechnology 2016, 27, 345710.

42 a) Y. Xiong, J. Chen, B. Wiley, Y. Xia S. Aloni, Y. Yin, J. Am. Chem. Soc. 2005, 127, 20, 7332-7333. b) Y. Xiong, B. Wiley, J. Chen, Z.-Y. Li, Y. Yin, Y. Xia, Angew. Chem. Int. Ed. 2005, 44, 7913-7917.

43 S. Seisko, M. Lampinen, J. Aromaa, A. Laari, T. Koiranen and M. Lundström, Miner. Eng 2018, 115, 131-141. 
